\title{
REFERENCIAÇÃO E LETRAMENTO: O USO DE EXPRESSÕES PRÉ-FABRICADAS
}

Vanda Maria Cardozo de Menezes

(Universidade Federal Fluminense)

\section{RESUMO}

0 artigo apresenta uma abordagem sociocognitiva do processo de referenciação, com o objetivo de verificar em que medida e de que maneira se pode atualizar ou, mesmo, confirmar as estratégias adotadas no tratamento do léxico no processo de letramento, na leitura e na escrita. Estudos sobre como as palavras são armazenadas na memória do usuário e sobre como são acessadas no uso da língua, em especial as teorias desenvolvidas a partir de pesquisas em psicolinguística, foram utilizados para a compreensão do processo de letramento e marcaram avanços nessa área. Em continuidade, se destacam os estudos cognitivistas, com a noção de categorização prototípica, e, mais atualmente, os estudos sócio-cognitivistas, com a noção de representação exemplar, com base na experiência dos falantes culturalmente situados. Uma aplicação desses estudos ao processo de letramento é demonstrada, neste artigo, por observações relativas ao acesso a estruturas pré-fabricadas no processo de referenciação.

PALAVRAS CHAVE: referenciação - letramento - expressões pré-fabricadas

\section{Introdução}

Pensando sobre as especificidades de nosso "fazer", sendo professora de português língua materna, observamos que, em relação aos colegas de outras disciplinas, não surpreendemos ou encantamos nos- 
sos alunos com a apresentação de conteúdos novos. Mas essa é uma decorrência da disciplina que ensinamos, pois trabalhamos com o que os alunos já sabem ou já vêm aprendendo desde que começam a interagir socialmente. Nosso mérito está, pois, na ampliação e na continuidade de "algo" que não se encerra na escola.

Em uma fase inicial, intensa e extensa, esse "algo" - saber e prática linguística sociocognitivamente amalgamados - a que nos referimos, pode ser chamado de letramento, processo que, para muitas crianças, inicia-se antes de sua chegada à escola, lembrando os estudos de Ferreiro e Teberosky (1979), envolve a fase de alfabetização e atravessa os primeiros anos do período escolar. Portanto, sob o esse ponto de vista, não mais cabem discussões sobre alfabetização e letramento, no sentido de esclarecer se são fases distintas , consecutivas ou paralelas. A alfabetização, independente do método adotado, é uma importante fase, pela qual necessariamente passa o processo de letramento, sem que ela - a alfabetização - precise deixar de ser também letramento, como nos lembra Magda Soares (2004, p. 14):

Dissociar alfabetização e letramento é um equívoco, porque, no quadro das atuais concepções psicológicas, linguísticas e psicolinguísticas de leitura e escrita, a entrada da criança (e também do adulto analfabeto) no mundo da escrita ocorre simultaneamente por esses dois processos: pela aquisição do sistema convencional de escrita - a alfabetização - e pelo desenvolvimento de habilidades de uso desse sistema em atividades de leitura e escrita, nas práticas sociais que envolvem a língua escrita - o letramento.

Não queremos dizer com isso que as discussões se tenham esgotado, queremos apenas firmar aqui é que, enquanto as reflexões se desenvolvem, podemos também cuidar da prática. E não se trata de práticas generalizadas que apenas demonstrem posicionamentos teóricos atualizados dos professores, como parece ter equivocadamente ocorrido com a "adoção em massa" do construtivismo nos anos de 1980 (cf. SOARES, M. 2004, p.10); trata-se, sobretudo, de partilhar conhecimentos teóricos específicos sobre aquisição e aprendizagem de leitura e escrita, que possam implicar práticas específicas, tanto somente para a fase de alfabetização, quanto para todo o letramento, sem a ambição de uma "mudança revolucionária”, em um e outro processo.

Assim considerando, tomamos, neste artigo, os estudos sobre referência sob a abordagem sociocognitiva (MONDADA e DUBOIS, 
2003; KOCH, 2002; MARCUCHI, 2004, 2007), para mostrar que, em muitos aspectos, esses estudos podem contribuir para apontar atitudes adequadas do professor nas atividades de leitura e produção de textos, bem como na atividade de avaliação dos textos produzidos. Dentre esses aspectos, nos encaminharemos, neste artigo, para uma questão específica, a das expressões lexicalizadas (expressões lexicais estabilizadas), também chamadas expressões pré-fabricadas, por Erman e Warren (2000).

Partimos, para tanto, da concepção de "memória semântica", amplamente estudada por teorias psicolinguísticas dedicadas, a partir dos anos 1950, ao estudo dos processos envolvidos na recepção e produção de mensagens (cf. KATO, 1986; SCLIAR-CABRAL, 1991), para observar similaridades, diferenças ou avanços em relação aos estudos sociocognitivos atuais, que propõem a concepção de "cognição compartilhada", também nomeada "cognição social" ou "cognição distribuída" (MONDADA e DUBOIS, 2003; MARCUSCHI, 2007), tendo como base a hipótese de que o uso comum recorrente - "socialmente adotado" - de uma expressão linguística contribui para sua estabilização posterior, configurando uma representação exemplar na memória (BYBEE, 2010). Dessa maneira, as representações exemplares são entendidas como representações da memória gradualmente enriquecida pelo uso; elas contêm, ao menos potencialmente, todas as informações que um usuário da língua, enquanto sujeito situado no mundo, pode aprender e depreender de sua experiência linguística.

\section{Teorias sobre memória semântica}

As discussões encaminhadas sob a perspectiva da Psicolinguística representam um avanço significativo dos esforços dos estudiosos da linguagem na compreensão do modo como organizamos o conhecimento linguístico. Os rumos tomados pelos estudos nessa perspectiva, entretanto, foram tão diferenciados e fragmentados, que acabou por se chegar a um excessivo número de subcampos teóricos de alguma forma desvinculados. Leonor Scliar-Cabral (1991, p.8) já nos adianta esse panorama, nas primeiras linhas de um histórico sobre a psicolinguística:

Um exame retrospectivo sobre os antecedentes, o surgimento e o desenvolvimento da psicolinguística tem a utilidade de servir como exemplo das inter-relações entre as ciências humanas e mesmo físicas e naturais do último século, da busca fáustica, porém mais 
uma vez destronada de uma explicação mais unitária sobre os processos envolvidos na recepção e produção das mensagens e do movimento pendular que enfatiza ora uma, ora outra as indagações, acionado pela teorias epistemológicas que lhe subjazem e pelo cenário histórico e cultural que lhe serve de pano de fundo.

Continuamos a citação de Scliar Cabral (1991, p. 8), para também expressar nossa posição sobre o modo equivocado como se posicionam os adeptos de "novas" teorias, ao ignorarem ou até mesmo desprezarem totalmente os estudos anteriores, sem o devido senso de responsabilidade acadêmica na crítica que fazem.

Sem embargo, os destronamentos sucessivos que limitam gradativamente a crença na posse ilimitada do saber (antropocentrismo) não são exclusivos da psicolinguística (...). Significam, dialeticamente, avanços, no sentido de uma delimitação mais precisa e não genérica de hipóteses firmemente ancoradas numa teoria coerente e que, portanto, possam ser passíveis de verificação.

Assim devem ser aqui interpretadas as menções aos problemas não bem resolvidos ou mesmo trazidos pela psicolinguística, pois, antes, há o reconhecimento dos avanços promovidos por essa abordagem na compreensão do processo de letramento - tenha sido o processo já denominado ou não, à época, por esse nome; tenha sido ele já compreendido, ou não, tal como o é atualmente.

No que diz respeito às teorizações sobre os processos de significação envolvidos na recepção e produção das mensagens, a psicolinguística assinala em seu desenvolvimento uma mudança de enfoque ao se ocupar de um falante-ouvinte, antes não considerado pela semântica tradicional, ainda que, nos estudos psicolinguísticos iniciais, os falantes apareçam idealizados e descontextualizados. Mary Kato (1986, p. 48) estabelece essa comparação, ao afirmar:

Na semântica tradicional, filosófica e linguística, o significado nada tem a ver com o conhecimento individual, mas sim com entidades abstratas, como traços semânticos, proposições e funções proposicionais. Na comunicação, entretanto, a extração do significado de um enunciado ou de um texto depende do que se tem na memória e da maneira como essa memória funciona.

E para melhor situarmos as posições aqui apresentadas sob a perspectiva da psicolinguística, cabe assinalar que, ao lado da linguística e da psicologia, também a teoria da informação serviu 
como embasamento e expressão das novas ideias. Tanto é que, numa segunda fase da psicolinguística, sob forte influência dos trabalhos de Chomsky, a partir do Syntactic Structures, 1957, o objeto da psicolinguística vem a ser os processos de codificação e de decodificação: "A língua é considerada como um código que permite gerar mensagens através de um canal, graças aos processos de codificação de que resulta o output (ou saída), produzido por um emissor, e de decodificação do input (entrada), pelo receptor." (cf. SCLIAR-CABRAL, 1991, p. 14)

Os modelos de estratégias de processamento (estratégias perceptuais), com base em experimentos realizados por Fodor, Garret e Bever, 1968 - inicialmente centrados em estruturas sintáticas, até mesmo como modo de questionar as diretivas das teorias de Chomsky -, a noção de estratégia deflagra o desenvolvimento de pesquisas cognitivas sobre processamento da linguagem, sobretudo da leitura (recepção), marcando, assim, uma terceira fase da psicolinguística, justamente a que mais nos interessa neste artigo, para tratarmos de memória semântica. (cf. SCLIAR-CABRAL, 1991, p. 29)

Miller ([1978] Apud SCLIAR-CABRAL, 1991, p. 55-56) enumera e detalha as informações necessárias e compatíveis entre si que refletem o conhecimento que um usuário tem quando as compreende num enunciado e quando as utiliza para transmitir s outrem se estados de consciência, a saber: 1) Fonológicas e/ou grafêmicas (inclusive os aspectos suprassegmentais e as pistas relevantes no sistema escrito; 2) Morfológicas; 3) Sintáticas; 4) Semânticas do radical; 5) Semânticas da sentença; 6) Semânticas textuais e pragmáticas.

Os desafios postos em pauta por Miller [1978], a nosso ver, já nos permitem constatar o caráter de continuidade nas abordagens mais atuais.

Mas ainda seguiremos pouco adiante no tema da "memória semântica", com as teorias que, apesar de "se prestarem a interpretações contraditórias”, irão contribuir para o desenvolvimento dos estudos atualmente referendados pela Linguística cognitiva.

Scliar-Cabral (1991, p. 56-59) cita quatro teorias sobre a significação: a teoria dos traços (Katz e Fodor, 1963); a teoria das redes semânticas (Collins e Quillian, 1969); a teoria dos protótipos (Rosch, 1973); e a semântica procedimental (Johnson-Laird, 1977).

A teoria dos traços é assim denominada por defender que a significação das unidades linguísticas é definida por marcadores se- 
mânticos que possuem traços binários do tipo [+] ou [-] animal; [+] ou [-] humano. Segundo Scliar-Cabral (1991, p.57), a crítica principal a este modelo reside na difícil sustentação da hipótese de que um usuário decompõe uma unidade em traços, toda a vez que chegar ao seu sentido.

A teoria das redes semânticas considera que os conceitos representados pelos usuários são ligados entre si por laços que representam as relações que une esses conceitos, como, por exemplo, relações de associação, especificação de atributos e inclusão numa mesma classe, esses últimos já se apresentam hierarquicamente. ScliarCabral (1991, p.58) ressalta que, embora esse modelo tenha sofrido críticas por não dar conta de alguns dados, muitas de suas hipóteses foram comprovadas e, após implementações, passou a se mostrar adequado a vários estudos relacionados à "inteligência artificial".

A teoria dos protótipos surge como resposta a problemas encontrados em teorias anteriores ao tratarem de definições e delimitações de categorias. Wittgenstein, já em 1953, apresentou uma crítica séria ao ponto de vista clássico de definição de algumas palavras. Desde então muitos outros estudiosos buscam uma outra concepção para a definição das categorias linguísticas. Mas foi com Eleanor Rosch, em 1973, que a teoria dos protótipos mais bem se formalizou. Rosch não apenas propôs o conceito de tipicidade, mas também elaborou e aplicou testes em que solicitava aos sujeitos que avaliassem cada membro de uma categoria pelo critério do quanto se assemelhavam, ou fossem típicos da categoria identificada. Taylor (1989), baseandose nos estudos de Wittgenstein e de Rosch, observa que muitas categorias da língua podem não ter limites nítidos e que isso não desmerece a utilidade comunicativa dessas categorias (é o caso do uso do infinitivo em português, em certos contextos mais pertencente à categoria “verbo", em outros, à categoria “nome”). Também os membros de uma dada categoria não apresentam necessariamente delimitação nítida; o grau de pertencimento a uma categoria deve ser depreendido conforme uma representação advinda do uso da língua (dessa maneira é que verificamos, por exemplo, se duas palavras podem ser consideradas "sinônimas" ou não).

A Semântica procedimental de Johnson-Laird (1977) opera com primitivos conceituais - constructos de natureza mais abstrata que os itens lexicais -, sem ignorar, porém, que a prática da comunicação pode interagir de maneira complexa com outras práticas, o que 
pode levar a uma constante renegociação dos usos vigentes numa comunidade de falantes. Gurevich et al (Apud BYBEE, 2010, p.17) apontou (mais tarde) que esses estudos foram utilizados para demonstrar que a retenção de palavra por palavra na memória nem sempre ocorre, e que, de fato, os resultados das pesquisas demonstram que a forma superficial das sentenças não se perde sempre de maneira total. Essa anotação é muito relevante para os estudos das construções lexicais e gramaticais, em desenvolvimento na atualidade.

Apresentadas brevemente as quatro teorias, queremos confirmar nosso maior interesse pela teoria dos protótipos, por estar ela mais bem integrada ao desenvolvimento dos estudos sobre referenciação no campo da Linguística do Texto, em consonância com o viés sociocognitivista.

Marcuschi (2007, p. 62) observa que se dá na linguística uma virada importante e necessária, de cunho cognitivista, em continuidade a uma outra já ocorrida em meados do século XX, de cunho pragmático, para o desenvolvimento dos estudos sobre como, pela mediação da linguagem, construímos o conhecimento da "realidade".

Hoje entra com alguma força na cena teórica das investigações a ideia de situar o foco mais nas atividades de construção do conhecimento e menos nas atividades de processamento, tal como se fez nas décadas de 70 e 80 no campo da Psicologia Experimental, quando se considerava a cognição no nível do indivíduo.

\section{Referenciação, categorização e representação exemplar}

Com o desenvolvimento dos estudos na perspectiva cognitiva, ocorrem inevitavelmente muitas revisões conceituais.

A concepção de sujeito da linguagem já se modificara muito, ao passar a ser reconhecida a existência de um sujeito psicológico, individual; e depois, a existência de um sujeito engajado, inserido numa ideologia. 0 que agora temos é uma consequência do reconhecimento de que os processos cognitivos efetivamente atuantes na linguagem não são próprios de apenas um sujeito e não são também criados, motivados ou ativados por um sujeito isolado. Temos, então, a concepção de cognição social. Marcuschi (2004, p. 280) utiliza a expressão cognição distribuída para explicar a mudança de foco: "se até há pouco tempo a cognição era um aspecto individual que ocor- 
ria na cabeça das pessoas, agora se torna um aspecto observável na relação intersubjetiva e no trabalho comum".

Vale a pena insistir nesse ponto, com mais um trecho de Marcuschi (2007, p.48):

Não importa se escrita ou falada, a língua não é autônoma e só opera como uma forma de apropriação do real pela mediação da experiência. Não de uma experiência direta e individual, mas uma experiência socializada, pois a língua não surge em cada um individualmente e se dá sempre como um evento sociocognitivo. A língua não é um fenômeno privado, dizia Wittgenstein enfaticamente.

A noção clássica de referência também é revisada, não mais se aceitando a simples afirmativa de que "a língua representa a realidade”, com possibilidade de se excluírem os sujeitos, ao se deduzir uma relação direta e objetiva entre língua e realidade. No mínimo diremos que "os sujeitos constroem realidades por meio da língua", para, em seguida, verificar que processos estão envolvidos nessa atividade de referenciação, como nomeiam Mondada e Dubois (2003, p. 20).

0 problema não é mais, então, de se perguntar como a informação é transmitida ou como o estados do mundo são representados de modo adequado, mas de se buscar como as atividades humanas, cognitivas e linguísticas, estruturam e dão um sentido ao mundo. Em outros termos, falaremos de referenciação, tratandoa, assim como à categorização, como advindo de práticas simbólicas mais que de uma ontologia dada.

A concepção de categorização também é revisada nos estudos cognitivos. Em vez de se pressupor um "mapeamento" da língua sobre as coisas (objetos da realidade) que já se encontrariam discretizadas no mundo real, começa-se a perceber o papel dos sujeitos na organização da língua e no modo como os textos são construídos e interpretados. Enfim, a questão é revisitada sob uma visão dinâmica. 0 sujeito não é apenas um indivíduo e a língua um código de que ele se apropria para conhecer o mundo, mas é especialmente um ser sociocognitivo que conhece o mundo e partilha esse conhecimento com outros sujeitos "na intersubjetividade das negociações, das modificações, das ratificações de concepções individuais e públicas do mundo" (MONDADA e DUBOIS, 2003, p. 20).

Não é difícil, portanto, notar mudanças nos mais variados enfoques, a partir do momento em que se reconhece a impossibilida- 
de de se fazer uma delimitação rígida das categorias linguísticas, já que elas são sociocognitivamente fundadas.

Aqui deve ser incluída a necessária revisão da oposição tradicionalmente estabelecida entre estabilidade e instabilidade, com atribuição de valores negativos a uma ou a outra situação, como se ambas não fossem motivadas pelo uso da língua. Um exemplo disso está numa concepção negativa generalizada a respeito das chamadas "expressões cristalizadas”, que já apontei em outro artigo (MENEZES, 2008, p. 302):

Nessa visão essencialmente dicotômica, as expressões lexicais multivocabulares são tomadas como agrupamentos definitivamente estáveis quanto à forma e ao conteúdo; como expressões feitas e acabadas, cujo uso não requereria dos falantes qualquer habilidade discursiva e não expressaria qualquer habilidade cognitiva ou comunicativa. Desse modo não é de se estranhar que essas expressões tenham sido designadas por termos que indicam o traço comum da repetição, considerada negativamente como indicativa de pobreza vocabular ("lugar-comum”, "clichê", "chavão", "frasefeita").

Devemos ao estudo de Erman e Warren (2000) a retomada mais recente da questão das "expressões cristalizadas", a que os autores chamam de prefabs (prefabricated constructions), definindo-as (ERMAN e WARREN, 2000, p. 32) como "uma combinação de base lexical, constituídas de no mínimo duas palavras que são consideradas como um item de escolha em bloco pelos falantes nativos". Baseados em pesquisa em textos jornalísticos escritos, os autores (ERMAN e WARREN, 2000) mostram que essas expressões podem apresentar graus diferentes de fixação e que o usuário se vale do princípio de idiomaticidade com muito mais frequência do que se costuma imaginar. Esse princípio se diferencia de outro também em atuação no processo de referenciação: $o$ princípio de escolha aberta. 0 primeiro diz respeito à constatação de que o usuário da língua tem à sua disposição um grande número de expressões já previamente construídas que constituem "escolhas simples", embora pareçam poder ser analisadas em segmentos. 0 segundo princípio representa a única opção apontada pelos estudos tradicionais, o da escolha aberta, que pressupõe que cada posição em um frase requer uma escolha e o falante sempre seleciona os termos, um a um; ou seja, palavra a palavra.

Com o trabalho de Erman e Warren (2000), toma-se conhecimento de discussões anteriores que remetem a uma nova noção sobre o armazenamento de dados linguísticos em nossa memória. Os auto- 
res chamam a atenção para a base cognitiva do princípio de idiomaticidade. Argumentam, com base nas pesquisas realizadas por Bollinger (1976), que, tendo em vista o fato de que o cérebro humano é capaz de armazenar na memória unidades extensas, seria mais natural trabalhar com a hipótese de que nós armazenamos um grande número de itens complexos, que manipulamos por meio de regras relativamente simples.

Esse modo de construção já fora também apontado por Coseriu ([1977] 1981, p. 143-161) sob o rótulo de "solidariedades léxicas". Aliás, cabe-me aqui registrar que o linguista também apresenta uma concepção à frente de seu tempo a respeito do que ele denomina "discurso repetido" (id. ibid. p. 113-118). Embora tendo que abandonar esse tipo de discurso em sua descrição estrutural do léxico, por considerar que as construções estabilizadas pela repetição não podem ser analisadas, "no sentido próprio do termo", E. Coseriu (1981, p.113) observa que

as línguas são antes de tudo técnicas históricas do discurso (ou do "falar"), mas as tradições linguísticas estão longe de conter somente essa técnica de falar, elas contém também "linguagem já falada", "pedaços" de discursos já prontos e que podem ser empregados novamente, em diferentes níveis da estruturação concreta da fala.

Bybee (2010, p. 14), ao tratar da "representação exemplar" na memória linguística (exemplar representation), enfatiza um aspecto importante desse tipo de representação: o fato de que "exemplares" servem para registrar detalhes da experiência linguística. "Representações exemplares são representações preciosas para a memória; elas contêm, ao menos potencialmente, as informações que um usuário da língua percebe em sua experiência linguística”.

Consideramos também importante salientar, em especial para os que estudam o processo de letramento, que a concepção de "representação exemplar", promovida pela experiência dos falantes no uso da língua, pode ser comprovada com dados de uso da língua em todos os níveis (fonologia, morfologia, itens lexicais, sintaxe das construções, semântica e pragmática, e propriedades do contexto social, físico e linguístico).

Neste artigo, lançaremos mão de estudos que vimos realizando sobre referenciação e lexicalização, para avaliar em que medida esses estudos podem interagir com as pesquisas atuais sobre letramento. 


\section{As expressões lexicalizadas e o processo de} letramento

De que modo os estudos teóricos sobre memória e categorização linguística podem contribuir para o ensino da língua materna? A questão é muito ampla, e não alcançaremos nosso objetivo de contribuir para atividades de letramento, se não dissermos logo o que pensamos sobre a relação entre teoria e ensino. Entendemos que não devemos esperar que tenhamos pronta toda "uma nova abordagem de ensino segundo uma dada teoria”, para que comecemos a esboçar nossas ideias sobre algumas atividades de ensino. Primeiro, porque uma abordagem mais ampla requer anos e anos de pesquisa; segundo, porque apostamos na complementaridade entre diferentes abordagens linguísticas.

Assim, em relação ao letramento, indagamos: i) Que contribuição poderá trazer o a concepção de referenciação como atividade sócio-cognitiva? ii) Que consequências poderá trazer a "teoria dos protótipos" e a de "representação exemplar" para a prática de uso variado e adequado do léxico no processo de letramento? iii) Que equívocos podem já ser resolvidos no tratamento das expressões lexicalizadas.

A mudança de foco no entendimento da referência, de uma propriedade da língua para uma atividade de significação que conjuga o individual e social, provoca a revisão de muitos conceitos e a reflexão sobre muitas atividades de letramento, em especial sobre atividades de leitura e compreensão. Em vez de se ler o texto e dele se extrair, simplesmente, a mensagem ou o tema, passa-se a trabalhar, exaustivamente, com a progressão referencial, como processo de (re) construção que vai "do título ao texto" e volta "do texto ao título" (cf. COSTA, 2013). Observam-se as escolhas lexicais, as estratégias anafóricas, as repetições, o paralelismo semântico e estrutural, bem como a quebra de paralelismo, as paráfrases, etc. Tudo isso sem necessidade de os alunos conhecerem a metalinguagem, ou seja, todos os rótulos técnicos, de que são exemplos os que acabamos de mencionar; eles poderão participar mais do processo de construção de "referentes" no contexto em que o texto é lido, levando em conta, na medida do possível, o contexto em que o texto foi produzido (o que nem sempre pode ser totalmente recuperado, mas para isso valem as “inferências”). 0 trabalho com: textos poéticos, manchetes de primei- 
ra página de jornal e leads, títulos de textos, editoriais, colunas, textos publicitários, charges e quadrinhos, enfim, com esses e outros gêneros não citados, servirá para o exercício de uma leitura, ao mesmo tempo, individual e conjunta; compartilhada não apenas na interação entre os que estão participando da atividade, mas também com os outros indivíduos sociais que, de alguma maneira, possam ser "corporificados" na leitura. Também a(s) "realidade(s)" construída(s) no passo-a-passo da atividade de referenciação estará relacionada a outras tantas "realidades" construídas e aceitas pela experiência de vida do "indivíduo social", cuja leitura e compreensão já se faz o tempo todo sócio-cognitivamente. 0 entendimento desse processo de leitura no âmbito da referenciação traz para sala de aula (ou para qualquer outro ambiente de letramento) o desafio de se fazer uma leitura de fato colaborativa. $\mathrm{Na}$ experiência, professores e alunos se mesclam; ficam exaustos e felizes.

Quanto às consequências das atualizações efetuadas mais modernamente na concepção de categorização linguística, muito já se discutiu. Pensando, então, de modo específico no processo de letramento, afirmamos que, a partir desse conhecimento teórico, os professorespoderão melhor compreender e identificar a razão de uma palavra ou construção mais genérica (prototípica) se encontrar mais facilmente disponibilizada para uso (a palavra "carro”, em relação a nomeações mais específicas, como "camionete", "pick-up", "Fiat Uno”, dita pelo proprietário daquele único veículo ao garagista de seu prédio); também, em sentido aparentemente contraditório, a razão de outra palavra ou construção menos genérica e menos representativa (atípica ou marginal) passar a ter representação exemplar, com sentido peculiar. Esta requer menor esforço no armazenamento na memória e no processamento on line do discurso (como a palavra "carroça" na frase "não é bem um carro, é uma carroça”, escolhida para expressar a qualidade inferior de um certo "carro"). Entram, assim, na prática de leitura, por exemplo, o exercício da contextualização, o resgate do conhecimento de mundo partilhado, as observações sobre diversidade linguística de vários tipos, os comentários sobre mudança linguística, o reconhecimento das atividades de criação na linguagem e dos vínculos com a tradição linguística, etc.

Sobre o tratamento das expressões lexicais pré-fabricadas, pesquisas relatadas por Erman e Warren (2000), comprovam a alta frequência desse tipo de expressões em textos diversos de variados 
gêneros. Em pesquisa realizada por nós (MENEZES, 2008), considerando um subgênero jornalístico, denominado "Informe" pelo já extinto Jornal do Brasil e "Painel" pelo jornal Folha de São Paulo, foram apresentadas as seguintes conclusões sobre expressões préfabricadas ou lexicalizadas (ou em processo de estabilização/ lexicalização): i) são usadas com maior frequência do que supomos; ii) têm alto rendimento comunicativo e assumem funções discursivas diversas, de acordo com o gênero (ou subgênero) do texto que constroem; iii) de certa forma, apresentam maior grau de estabilidade referencial, pois funcionam em bloco e são coletivamente préfabricadas.

Com base nos estudos de Bybee (2010), acrescentaremos que as expressões pré-fabricadas demonstram a representação das experiências sociocognitivamente partilhadas pelos usuários da língua na categorização e organização linguística. Assim sendo, não é de admirar que elas sejam frequentemente usadas, uma vez que se encontram prontas, memorizadas e, em geral, com sentido estabilizado, ou seja, com relativa garantia comunicativa. A estabilização referencial da expressão se torna, por vezes, tão firme, que o leitor se surpreende quando um produtor de texto se utiliza das mesmas palavras que constituem a expressão, elaborando o mesmo arranjo, mas com sentido diferente, o chamado sentido "original" ou "literal".

Cabeça feita

0 atacante Leandro só aceitou dar uma entrevista ontem depois que o repórter prometeu não perguntar sobre seu novo visual, com aplique de cabelo. (Folha de São Paulo, 20/11/2007).

Ao ler o título desse texto, o leitor cria a expectativa de ler adiante algo sobre alguém que tem uma opinião própria e não se rende à influência de outros. No texto, essa ideia é inicialmente confirmada, pois o jogador Leandro só aceitou ser entrevistado sob suas condições, sem abrir exceções. Entretanto, a expressão "cabeça feita" mostra a mudança no penteado do jogador que passou a usar aplique de cabelo. Neste sentido, há, no final, a desconstrução da expressão lexicalizada, que possivelmente foi primeiramente acessada.

Exemplos como esse apresentado, com a expressão "cabeça feita”, servem bem para trabalhar a atividade de referenciação, enquanto atividade que se faz discursivamente e que se utiliza de recursos linguísticos sociocognitivamente estabelecidos. 
Para finalizar, cabe fazer um comentário sobre equívocos que ainda devem ser desfeitos com relação ao emprego de expressões pré-fabricadas. 0 primeiro deles é o pensamento de que o emprego dessas expressões deve, de antemão, ser desaconselhado pelo professor, uma vez que tal emprego demonstraria "pobreza vocabular". 0 segundo está relacionado ao primeiro e diz respeito à indevida intervenção no texto do aluno, no sentido de apontar a inadequação no uso de uma expressão estabilizada. Ora, em geral, isso ocorre porque o aluno considera que a expressão dá conta do que ele quer dizer e, ainda, que dá conta do que um determinado grupo social pensa ou diz a respeito do mesmo assunto. E não nos esqueçamos de que na maioria das vezes é apresentada uma mesma proposta de redação a um dado grupo de alunos. Deve ser, pois, mais do que esperado e, principalmente, deve ser bem compreendida pelo professor a recorrência de uma dada expressão lexicalizada, uma vez que o grupo compartilha sociocognitivamente experiências de uso da linguagem. Sem contar as injustiças que se cometem na correção de redações em exames de larga escala!

\section{Considerações finais}

Ao final deste artigo, nos sentimos entusiasmados com a possibilidade de os estudos em Referenciação se agregarem aos muitos outros estudos que colaboram com as pesquisas em Letramento. Reiteramos nossa posição de que não precisamos mais esperar que se formule todo um arcabouço teórico que dê conta de todos os aspectos linguísticos, em toda sua complexidade, para que, então, comecemos a verificar como essa concepção teórica se aplica ao ensino. Antes disso, podemos começar a indagar como um estudo que estamos realizando, ou que já tenhamos realizado em momento anterior, pode de alguma forma contribuir para o ensino. Nesse sentido, acreditamos que as atividades com o "léxico", na leitura e na escrita, podem ser produtivamente ampliadas, a partir da concepção de que as categorias linguísticas são representações exemplares construídas pelos usuários (na fala e na escrita; como falantes ou produtores, ouvintes ou leitores), sempre e ao mesmo tempo, individuais e coletivos, daí o uso bem oportuno da expressão sujeitos sociocognitivos. 
This paper presents a socio-cognitive approach of the referentiation process, in order to check to what extent and in which way the strategies adopted in the treatment of the lexicon in the literacy process can be updated, or even confirmed, in reading or in writing. Studies on how words are stored in the user memory and on how they are accessed - while language is being used - represent a great advance in understanding the literacy process, especially for psycholinguistics research. Besides, this paper highlights the prototypical notion of categorization treated in the cognitive studies as well as the notion of exemplar representation in the socio-cognitive area, which is based on the experience of culturally-situated speakers. A practical approach of these studies to the literacy process is demonstrated in this paper, taking into consideration prefabs in the referentiation operation.

KEYWORDS: referentiation - literacy - prefabs

\section{REFERÊNCIAS}

BOLLINGER, Dwight. Meaning and memory. In: Forum Linguisticum. [S.l.], v. 1, p.1-14, 1976.

BYBEE, Joan Language, Usage and Cognition. Cambridge: Cambridge University Press, 2010.

COSERIU, Eugenio. Principios de Semántica Estructural. 2 ed. Madrid: Gredos, [1977] 1981.

COSTA, Wagner Alexandre dos Santos. Do título ao texto/ Do texto ao título: o processo de estabilização da referência em notícias do jornal 'Meia Hora'. Tese de Doutorado. Niterói, RJ: Universidade Federal Fluminense, 2013. ERMAN, Britt; WARREN, Beatrice. The idiom principle and the open choise principle. Text, Berlim, n.20, p. 29-62, 2000.

FERREIRO, Emília; TEBEROSKY, A. Psicogênese da língua escrita. Trad. de Diana Myrian Lichtenstein et al. Porto Alegre: Artes Médicas, 1986.

KATO, Mary A. No mundo da escrita: Uma perspectiva psicolinguística. São Paulo: Ática, 1986. 
KOCH, Ingedore G. Villaça. Desvendando os segredos do texto. São Paulo: Cortez, 2002.

MARCUSCHI, Luiz Antonio. O léxico: lista, rede ou cognição social? In: ILARI, Rodolfo. Sentido e Significação. São Paulo: Contexto, 2004.

2007. . Cognição, Linguagem e práticas interacionais. Rio de Janeiro: Lucerna,

MENEZES, Vanda M. Cardozo de. Estruturas léxicas do português: contribuição da teoria lexemática de Eugenio Coseriu. Dissertação de Mestrado. Niterói, RJ: Universidade Federal Fluminense, 1990.

. Expressões lexicalizadas no português brasileiro: construção conjunta e uso comunitário do léxico. In: RONCARATI, Claudia; ABRAÇADO, Jussara. Português brasileiro II: contato linguístico, heterogeneidade e história. Niterói, RJ: Editora da Universidade Federal Fluminense (EdUFF), 2008, p. 311-333.

MONDADA, Lorenza; DUBOIS, Danièle. Construção dos objetos de discurso e categorização: Uma abordagem dos processos de referenciação. In: CAVALCANTE, Mônica Magalhães; RODRIGUES, Bernadete Biasi; CIULIA, Alena. Referenciação. São Paulo: Contexto, 2003.

SCLIAR-CABRAL, Leonor. Introdução à Psicolinguística. São Paulo: Ática, 1991.

SOARES, Magda. Letramento e alfabetização: as múltiplas facetas. In. Revista Brasileira de Educação, 5, 2004, p.14. www.scielo.br/rbedu

TAYLOR, J. Linguistic categorization: prototypes in linguistic theory. Oxford: Oxford University Press, 1989.

Recebido em 23 de maio de 2015

Aprovado em 30 de maio de 2015 